AperTO - Archivio Istituzionale Open Access dell'Università di Torino

\title{
An update on the Early Pleistocene herpetofauna from Pirro Nord
}

\section{This is a pre print version of the following article:}

Original Citation:

\section{Availability:}

This version is available http://hdl.handle.net/2318/127372

since

Terms of use:

Open Access

Anyone can freely access the full text of works made available as "Open Access". Works made available under a Creative Commons license can be used according to the terms and conditions of said license. Use of all other works requires consent of the right holder (author or publisher) if not exempted from copyright protection by the applicable law. 


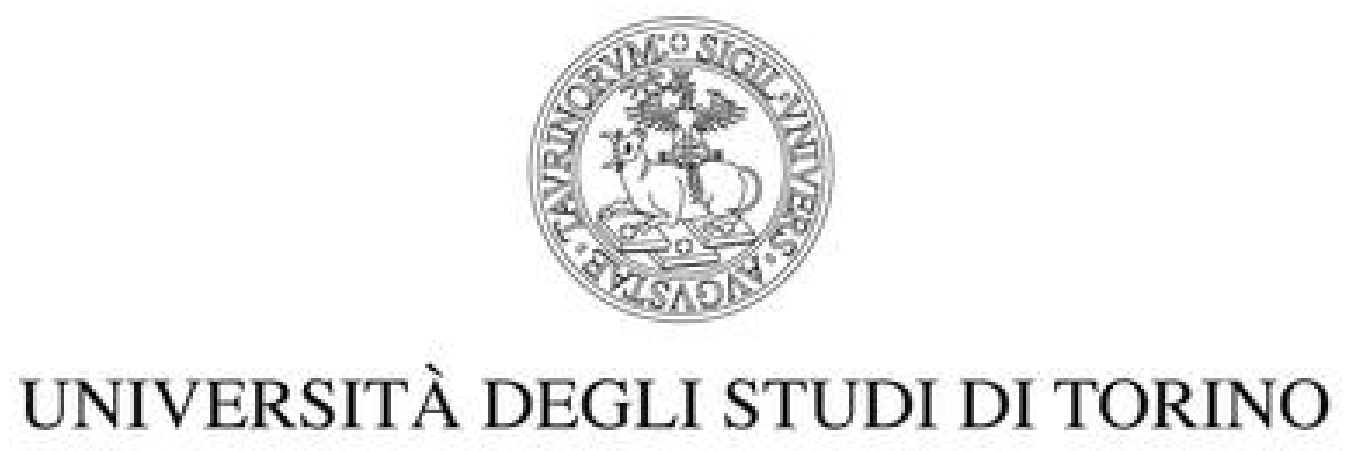

This is an author version of the contribution published on:

\section{DELFINO, M. ATZORI}

An update on the Early Pleistocene herpetofauna from Pirro Nord PALAEONTOGRAPHICA ABTEILUNG A PALAOZOOLOGIE, STRATIGRAPHIE (2013) 298 
An update on the Early Pleistocene herpetofauna from Pirro Nord

Delfino M. \& Atzori M. 


\section{Zusammenfassung}

Die vorausgehende Analyse von tausenden kürzlich gesammelten Überresten von Amphibien und Reptilien der Frühen Pleistozän Gegend von Pirro Nord erlaubt, die ehemalige Fauna Liste zu aktualisieren. Ein Mitglied der Familie Pelobatiae, verwiesen auf Pelobates sp., wird zum ersten Mal im südlichen Italien gemeldet. Einige Schädelelemente unterstützen die vorherige Identifizierung der Schlangen Hierophis viridiflavus und Natrix natrix. Der Fund von wenigen anguiden Exemplaren in Schichten mit Beweisen für die gemischte Anwesenheit von neogenen und pleistozänen Fossilien verursacht Zweifel an dem Alter des einzigen Pseudopus Überrestes über den in einer vorherigen Studie berichtet wurde. Im Grossen und Ganzen bestätigen und diese neuen Funde die Einzigartigkeit der Gargano herpetofaunistischen Sammlung, in Bezug auf die Anzahl der Überreste, Erhaltung, Diversität und deshalb deren informativen Eigenschaften.

Schlüsselwörter: Pelobates, Pseudopus, Hierophis, Natrix

\section{Summary}

The preliminary analysis of thousands of newly collected remains of amphibian and reptiles from the Early Pleistocene locality of Pirro Nord allows to update the former faunal list. A member of the family Pelobatidae, referred to Pelobates sp., is reported for the first time in southern Italy. A few cranial elements support the previous identification of the snakes Hierophis viridiflavus and Natrix natrix. The finding of few anguid remains in layers with evidences for the presence of Neogene fossils mixed with Pleistocene ones, casts doubt on the age of the single Pseudopus remain reported in a previous study. On the whole, these new materials confirm and strengthen the uniqueness of the Gargano herpetofaunistic assemblages in terms of number of remains, preservation, diversity, and therefore informativeness.

Keywords: Pelobates, Pseudopus, Hierophis, Natrix 


\section{Contents}

Introduction

Materials and Methods

Systematic Palaeontology

Discussion and Conclusion

Acknowledgements

Literature References

\section{Introduction}

The abundant fossil remains from the Early Pleistocene fissure fillings opening in the quarries on the northwestern slopes of the Gargano promontory (Apricena, Apulia, Italy) testify for a well diversified herpetofauna (Delfino, 1996, 1997, 2001). Delfino \& Bailon (2000) identified more than 14000 remains, referred to the 18 different taxa, from the sites then called as Cava dell'Erba and Cava Pirro and now comprehensively known as Pirro Nord (see among others: De Giuli \& Torre, 1984; De Giuli et al., 1987; Abbazzi et al., 1996; Arzarello et al., 2006). The faunal list, revised according to the current nomenclature, is the following: Mesotriton cf. M. alpestris, Lissotriton vulgaris group, Bufo bufo, Bufo viridis group, Hyla arborea group, Pelophylax sp., Testudo hermanni, Emys orbicularis group, Mauremys sp., Pseudopus sp., Podarcis sp., Lacerta sp., Blanus sp., Hierophis viridiflavus, Zamenis longissimus group, Coronella cf. C. austriaca, Natrix natrix, and Vipera aspis group. Some of these taxa are represented by hundreds or even thousands of remains (as the toads and the terrapins) whereas others are quite rare. The rarest taxon is the glass lizard, Pseudopus sp., which is represented by a single remain: an isolated laterodorsal osteoderm. New excavations in the Pirro Nord area, recently yielded several thousands of new vertebrate remains of Early Pleistocene age along with the flint lithic artifacts testifying for the oldest human evidence in Europe (Arzarello et al., 2006). Even if the selection and identification of these new 
materials is still in progress, it is possible to state that the herpetofaunistic remains are extremely abundant and that their study will considerably increase the knowledge of this assemblage. This paper is dedicated to few selected remains whose relevance allows widening the faunal list or to discuss and support previous identifications.

\section{Materials and Methods}

Anatomical nomenclature follows Bailon (1999) and Sanchiz (1998) for anurans, Szyndar (1984) and Holman (2000) for snakes.

The taxonomic nomenclature follows Sindaco et al. (2006) and Lanza et al. (2007). Accordingly, Alpine newts are referred to genus Mesotriton, waiting further support for the validity of Ichthyosaura as recently proposed by Speybroeck \& Crochet (2007). The remains of the green toad are referred to Bufo viridis group on the basis of the recent molecular evidences for the presence in peninsular Italy of at least three species (Stöck et al., 2008) which are apparently not identifiable on a skeletal basis.

Abbreviations: DSTF: Dipartimento di Scienze della Terra, Firenze; MNCN: Museo Nacional de Ciencias Naturales, Madrid; PU: Dipartimento di Scienze della Terra, Torino.

\section{Systematic Palaeontology}

Amphibia Linnaeus, 1758

Anura Rafinesque, 1815

Pelobatidae Bonaparte, 1850

Pelobates Wagler, 1830

Pelobates sp.

Referred material: PU 106783 (PN 21), 1 trunk vertebra

Text-fig. 1 


\section{Description:}

The vertebra is nearly perfectly preserved. The procoelous centrum is $3.2 \mathrm{~mm}$ long from the ventral edge of the cotyle to the posterior tip of the condyle; it is uniformly convex along its entire length. The deep cotyle is slightly oval shaped (with a horizontal main axis) possibly because of a moderate erosion of its rim. The condyle is robust and roundish, dorsally, and partly laterally, well delimited from the centrum by a step. The neural canal, nearly as wide as tall, is much larger than the cotyle and the condyle. The neural arch is anteroposteriorly long, dorsoventrally flattened, and shows a moderate constriction in dorsal or ventral view. The anterior edge is markedly concave (nearly Vshaped), the posterior one has a pointed median process that slightly surpasses the posterior edge of the postzygapophyses. The neural arch has a weak sagittal ridge, but marked ridges delimit the two vaguely triangular depressions placed laterally to the median process representing the neural spine. The pre- and postzygapophyses are dorsally tilted. The prezygapophyseal facets are vaguely roundish. The transverse processes are relatively slender, slightly flattened in a vertical plane, tapering distally, and have a truncated apex; in dorsal view, they are anterolaterally directed (they form an angle of about $45^{\circ}$ with the sagittal axis); in posterior view, they are slightly inclined ventrally.

\section{Discussion:}

The morphological traits described above are congruent with the vertebral morphology of the genus Pelobates. The roundish cotyle and condyle, the anteroposterior elongation of the neural arch, and the well developed neural spine clearly support such identification (Bailon, 1999). The size and orientation of the prezygapophyseal processes, along with the development of the median process of the posterior edge of the neural arch allow suggesting that the fossil could be the sixth vertebra (the fifth posterior to the atlas). As for the specific identification, the triangular depressions bordered by ridges and placed laterally to the neural spine are not present in the available comparative 
specimens of $P$. cultripes (MNCN 18039, 18047), $P$. fuscus (DSTF 27, 28, 54, 181), and $P$. syriacus (MNCN 18091, 19785). In all these specimens, the bony lamina between the two ridges delimiting the triangular depressions in the fossil vertebrae from Pirro Nord (therefore the floor of the depressions) is usually not developed at all, or so narrow that it is limited to the apex of the triangle. PU 106783 is therefore referred to genus rank.

REPTILIA Laurenti, 1768

Serpentes Linnaeus, 1758

Colubridae Oppel, 1811

Hierophis viridiflavus Lacépede, 1789

Referred material: PU 106784 (PN 19), 1 left palatine; PU 106785 (PN 19), 1 left frontal; PU 106786 (PN 19), 1 incomplete braincase; PU 106787 (PN 19), 1 right prootic; PU 106788 (PN 19), 1 supraoccipital; PU 106789 (PN 19), 1 left quadrate; PU 106790 (PN 19), basiparasphenoid; PU 106791 (PN 19), 1 basioccipital

Text-fig. 2-6

\section{Description}

The left palatine PU 106784 (Text-fig. 2A) is well preserved and $11.2 \mathrm{~mm}$ long. This element hosts 10 teeth positions; the first tooth if broken off at the base; the acrodont and isodont teeth are preserved in positions three, five, seven, and nine (the other were occupied by non functional teeth); they are elongated, pointed, curved and posteriorly directed (the last two also a little medially). The vomerine process, corresponding at least to the teeth positions from four to seven, is wide and deeply concave in medial direction; it develops a pointed choanal process medioventrally directed. The posteroventrally directed maxillary process is relatively short and stout; it corresponds mostly to teeth positions four and five. The posterior end of the palatine is markedly bifurcated for the articulation with the pterygoid; the dorsal process is relatively stout. A large maxillary nerve 
foramen opens anteriorly to the maxillary process; it gives origin to a deep furrow anteriorly directed.

The left frontal PU 106785 (Text-fig. 2B) is complete; it is $8 \mathrm{~mm}$ long. The septomaxillary process is well defined, tall, and narrow, whereas the internal premaxillary process and the external premaxillary process are weakly expressed. Dorsal to the internal premaxillary process, the articular surface for the prefrontal has a triangular shape. The trabecular ridge is relatively tall and has an undulate profile in lateral view. Two evident foramina pierce the lateral wall close to its posterodorsal corner. The lateral edge of the bone is deeply concave whereas the dorsal surface only slightly.

The incomplete braincase PU 106786 (Text-fig. 3) is $14.5 \mathrm{~mm}$ long. It comprises postorbitals, parietal, supraoccipital, prootics, and exoccipitals. With the exception of the parietal, whose anterior wall is slightly damaged, all the elements are completely preserved, but sutures among them are not well visible on the external surface (they are clear on the internal surface). The postorbitals (which are always fused with the parietal) are rather robust and moderately long; they originate an evident laminar crest that is visible in lateral view, close to the anterior edge of the parietal. The anterior edge of the parietal is on the whole straight, the lateral walls are convex, and the dorsal surface is rather flat. The lateral processes located close to the postorbitals are proportionally massive and markedly developed, even if less protruding than the postorbitals. The two parietal crests converge on the dorsal surface of the parietal and become parallel close to its posterior edge; the crests are approximately straight or slightly concave. The evident parietal foramina, in number of two, are located in the posterior sector of the dorsal area. The supraoccipital has a shape slightly different from the isolated element PU 106788 (see below) in having all the visible dorsal surface occupied by the supraoccipital area (due to the absence of evident sutures, it is not clear if the posterior area is visible in posterodorsal view). The occipital crests are extremely developed in posterodorsal direction. The sagittal crest is distinctly raised and is originated by the confluence of the two parietal crests. Two small occipital foramina are located close to the anterior edge on the left, 
whereas the two on the right are located more posteriorly and close to the lateral edge. The prootics are characterised by a well developed and irregular supraoccipital crest which corresponds to a significant change in the slope of the lateral wall of the braincase (the area dorsal to the crest is nearly flat). In both the prootics, the anterior aperture hosting the foramen for the maxillary branch of the trigeminal nerve is slit-like and is associated to a couple of tiny foramina located above and below the aperture (on the left side, the lower foramen is united with the major aperture). The posterior aperture hosts a the large foramen for the mandibular branch of the trigeminal nerve and three smaller foramina, the lower of which should correspond to the facial nerve. The circumfenestral crest delimits the markedly concave and wide otic notch. The exoccipitals are characterized by an occipital crest expanded in posterior direction. The postoccipital protuberance is likewise expanded. The exoccipitals tubercle is proportionally massive. The posterior wall of the otic aperture is deeply concave. The foramen for the vagus-hypoglosal nerve is separated by a sort of crest from the posterior corner of the otic aperture; two accessory foramina are located on the external surface of the exoccipitals. The postoccipital foramen is placed at the posteroventral corner of the postoccipital protuberance, close to the ventral end of the occipital crest.

The isolated right prootic PU 106787 (Text-fig. 4A) is well preserved. It is mm 4.0 long and 5.3 $\mathrm{mm}$ tall. The supraoccipital crest is not well marked and corresponds to some irregularities of the surface of the bone. The anterior aperture is elongated and hosts a single large foramen for the maxillary branch of the trigeminal nerve. The posterior aperture hosts the large foramen for the mandibular branch of the trigeminal nerve (not visible in lateral view) and the small foramen for the facial nerve. The otic notch, delimited by the circumfenestral crest, is rather large.

The supraoccipital PU 106788 (Text-fig. 4B) is completely preserved. It is $3.1 \mathrm{~mm}$ long and 4.2 mm wide. The anterior edge, showing the irregular suture with the parietal, is deeply concave; the posterior edge is convex and pointed. The sagittal crest is present both on the supraoccipital area and in the posterior one. The supraoccipital area is concave and it is much larger than the posterior area. Irregular supraoccipital foramina open at mid height, but close to the lateral edge, of the 
supraoccipital area. The occipital crests meet each other approximately at the centre of the bone; they are distinctly raised and slightly overhanging posteriorly. The left quadrate PU 106789 (Text-fig. 5) is perfectly preserved. It is $11.0 \mathrm{~mm}$ long. The dorsal region of the bone is distinctly flaring. The dorsal crest is convex; it is anteriorly overhanging and truncated. The anterolateral edge is nearly straight whereas the posteromedial edge is concave. The stapedial process is oval-shaped; its ventrolateral edge is free and visible in lateral view. The quadrate crest is well developed and imparts to the lateral surface of the bone a marked concavity. The trochlea quadrati is strongly built; the lateral hemicondyle is more developed than the medial one.

The basiparasphenoid PU 106790 (Text-fig. 6A,B) is not complete because the parasphenoid process is broken off. The preserved portion is $9.0 \mathrm{~mm}$ long. In ventral view, this element is characterized by evident pterygoid and basisphenoid crests converging towards the small central area. The basisphenoid crest develops in a nearly sagittal plane, whereas the pterygoid crests are slightly developed in anterior direction. The region anterior to the central area is medially convex, whereas the lateral areas are concave. The suborbital flange is convex but does not develop any process. The basipterygoid processes are weakly developed. The median process at the posterior edge of the postpterygoid area, therefore along the suture with the basioccipital, is distinctly prominent. The anterior carotid foramina pierce the basiparasphenoid just anteriorly the pterygoid ridges. The common foramina open approximately in the centre of the postpterygoid area. Two unnamed foramina are placed medially, and slightly posteriorly, to the common foramina, close to the basisphenoid crest. In dorsal view, it is possible to observe that the parasphenoid process is broken just posteriorly to the frontal step. The trabecular groves are deep and evident. The trabecular processes are only modestly developed. The pituitary fossa is pentagonal in shape, large, deep, and well defined. The abducens nerve foramina are small but well visible. The notches for the sympathetic nerve are so well delimited medially, dorsally, and ventrally, that they seem incomplete foramina (not visible in dorsal view). 
The basioccipital PU 106791 (Text-fig. 6C) is perfectly preserved. It is $5.8 \mathrm{~mm}$ long and $6.5 \mathrm{~mm}$ wide. The anterior edge of the element hosts a marked notch for the posterior process of the basiparasphenoid. The basioccipital crest develops three subequal processes. The basioccipital tubercles distinctly protrude in lateral direction. The median crest is absent. On the ventral surface of the basioccipital, a foramen is located at the centre of the bone (apparently it does not pierce the bone). The occipital condyle is wide and robust.

\section{Discussion}

The skeletal elements described above have been referred to $H$. viridiflavus on the basis of the several diagnostic characters. As for the palatine, characteristic are the number of teeth positions, the shape and position of the vomerine and maxillary processes, as well as the markedly bifurcated posterior tip. The braincase is characterised by a mixture of characters, most of which fit with the morphology of $H$. viridiflavus: relevant are the straight anterior edge of the parietal, the flat dorsal surface of the parietal in the area between the parietal crest, the parietal crests converging on the parietal, the moderate development of the supraoccipital crest of the prootic, and the relatively large otic aperture; minor characters differing from the morphology of the available comparative specimens of $H$. viridiflavus are the lateral development of postorbitals exceeding the one of the comparative specimens of this species, and the parietal crest delimiting a triangular surface with slightly concave sides instead of rectilinear or slightly convex sides. The prootic has a weakly developed supraoccipital crest, an elongated foramen for the maxillary branch of trigeminal nerve, and a circumfenestral crest delimiting a wide otic notch. The supraoccipital has the occipital crests not reaching the anterior edge of the bone, a moderately developed posterior area, and an evident sagittal crest. The quadrate has a convex dorsal crest anteriorly overhanging and a moderately large, oval stapedial process clearly visible in lateral view. The basiparasphenoid is characterized by strongly developed pterygoid and basisphenoid crests, the pterygoid crests do not reach the posterolateral edges of the bone, the central area is rather small, the posterior process is narrow but 
well developed, the anterior orifices of Vidian canal open close to the pterygoid crests. The basioccipital has a narrow but evident anterior notch, and the tubercles developed on the basioccipital crest are subequal in size. The cranial elements described above support the presence of $H$. viridiflavus at Pirro Nord, a taxon previously identified mostly on the basis of isolated vertebrae.

Natrix natrix Linnaeus, 1758

Referred material: PU 106792 (PN19), 1 left frontal; PU 106793 (PN19), 1 parietal; PU 106794 (PN19) 1 basiparasphenoid

Text-fig.: 7, 8

\section{Description}

The well-preserved left frontal PU 106792 (Text-fig. 7A) is $5.8 \mathrm{~mm}$ long. Despite apical erosion, the septomaxillary process is clearly tall and expanded in a laminar structure. The internal premaxillary process is by far the largest: it is robust, elongated in anterolateral direction, and pointed. The external premaxillary process is a modest bent of the lateral edge of the frontal. The trabecular ridge is developed in a laminar-like structure whose ventral edge is markedly undulated in lateral view. The anterior three fourth of the lateral edge of the dorsal surface develop a laminar structure that confers to the bone a irregularly straight lateral profile (which is frequently deeply concave in most snakes; see for example Text-fig. 2B); an evident notch corresponds to the posterior fourth which is devoid of the lateral bony lamina. Two foramina are located at the base of the above mentioned lamina.

The parietal (with fused postorbitals) PU 106793 (Text-fig. 7B) is complete. It is $9.6 \mathrm{~mm}$ long and $11.1 \mathrm{~mm}$ wide. The postorbitals are relatively slender; they are longer than the anterior lateral processes of the parietal. The parietal is characterized by a deeply concave anterior edge; anterior lateral processes moderately robust; parietal crests not converging on the dorsal surface of the bone; 
dorsal surface rather flat, with the exception of a sagittal shallow depression which becomes more deep in the posterior sector between the parietal crests; parietal foramina not present. The basiparasphenoid PU 106794 (Text-fig. 8) is perfectly preserved. It is $10.7 \mathrm{~mm}$ long. The parasphenoid process is moderately long and tapers gradually to a point. In ventral view, there is only a hint of the basisphenoid crest. The pterygoid crests are more evident but weakly developed; they are placed in the posterior sector of the bone and therefore the postpterygoid area is relatively small; the left crest is nearly sigmoid-shaped, the other can be better defined as curved; they do not actually converge into a point, but become nearly parallel in anterior direction. The central area is rather large. The lateral areas are moderately concave. The suborbital flanges are markedly convex and develop a tubercle like structure (best seen in ventral view; the left one is damaged). The basipterygoid processes are well developed. There is no medial process at the posterior edge of the postpterygoid area. The anterior carotid foramina are relatively large and well visible; they are not located near the pterygoid crests. The common foramina are small and nearly hidden by the pterygoid crests in external view. In dorsal view, the frontal crest becomes progressively taller in anterior direction without any significant dorsal step. The trabecular groves are narrow and deep. The trabecular processes are underdeveloped. The pituitary fossa has vaguely the shape of a chestnut. The abducens nerve foramina are very small. The notches for the sympathetic nerve are weakly developed (the right one is much better defined than the left).

\section{Discussion}

The referral of the few cranial bones described above to Natrix natrix is based on the following characters: the development of the internal premaxillary process and of the lateral bony lamina of the frontal (which produces a distinct posterior notch); the relative development of the postorbitals; the concave anterior edge of the parietal, its crests not converging and delimiting a posterior concavity of the dorsal surface of the element; the weakly developed pterygoid crests that reach the posterolateral edge of the basiparasphenoid, the large central area of the latter, the large anterior 
orifices of Vidian canal that are not (not even partially) covered by the pterygoid crests in ventral view.

\section{Discussion and Conclusion}

The analysis of few selected skeletal elements recently collected at Pirro Nord allowed identifying a family, Pelobatidae, not yet reported for this Early Pleistocene assemblage, and to support, on the basis of informative cranial elements, the identifications of Hierophis viridiflavus and Natrix natrix which were previous based mostly on isolated vertebrae (Delfino, 1996; Delfino \& Bailon, 2000).

Pelobates - The presence of Pelobates in southern Italy is of exceptional relevance because it is the only occurrence outside its current Italian range which is restricted to the Po Plain at present (Sindaco et al., 2006; Lanza et al., 2007). Actually, this genus is quite rare in the Italian fossil record, being recorded only in the Middle Pliocene of Arondelli (Piedmont Region; VergnaudGrazzini, 1970). The revision of the remains from the Verona area previously referred to Pelobates fuscus indicate that they certainly belong to the green toads group (Delfino, 2002, and literature therein). Therefore, the presence of Pelobates in the fissure fillings of Pirro Nord represents an unexpected finding which significantly widens the ancient range of this genus in the Italian Peninsula. The present range of Pelobates clearly shows a marked relictual nature (mostly in its easternmost sector), in some cases supported by the finding of fossil or subfossil remains in areas where it is currently absent (see for an example from the eastern Mediterranean see Delfino et al., 2007 a). As far as Italy is concerned, due to the current limited range of Pelobates, the extreme rarity of its fossils, and, above all, the referral at genus rank of the Pirro Nord single vertebra, it is not possible to draw any general conclusion about the biogeographic history of this genus. However, it is tempting to underline that a former continuous range through the peninsula seems unlikely at present, whereas a Quaternary trans-Adriatic dispersal of Pelobates could be evaluated in agreement with the biogeographic history of at least one member of the herpetofauna of southern Italy, the snake Zamenis situlus (Bologna \& Mazzotti, 2006). 
Hierophis and Natrix - Neogene and Quaternary fossil snakes are mostly represented by isolated vertebrae whereas cranial elements are often underrepresented, frequently not collected or not identified as such, and therefore generally not studied even if they provide reliable diagnostic characters (less variable than those of the isolated vertebrae). At the same time, the study of fossil cranial remains is hindered by the absence of exhaustive descriptions of the European taxa (among the few, but partial, exceptions are Szunyoghy, 1932; Szyndlar, 1984; Venczel, 2000). Therefore the identification of the remains from Pirro Nord has been mostly based on direct comparison with extant specimens. The relatively high numbers of snake cranial elements from the Pirro Nord assemblage will allow verifying the former identifications realized on the basis of isolated vertebrae. The analysis of part of these cranial remains, reported in this work, already confirmed the presence of Hierophis viridiflavus and Natrix natrix.

Pseudopus - The cross checking of the occurrences of different microvertebrates in the karstic fissures sampled at Pirro Nord (F. Marcolini \& F. Masini, pers. comm.) resulted in indications of the presence of rare Neogene fossils within the Pleistocene assemblage, a fact possibly due to contamination during collection of the remains. As far as the herpetofauna is concerned, it is therefore possible that the single discogossid vertebra PU 106795 from PN 12b, as well as the anguid osteoderms PU 106796 from PN 10E and PU 106797-106798-106799 from PN 10F are not of Pleistocene age, as the rest of the elements found along with them, but older. Noteworthy is that both these families have been previously identified in the rich herpetofauna coming from the Late Miocene-Early Pliocene deposits of the same karstic complex (Delfino, 2002; Delfino et al., 2007 b).

This casts doubts on the single Pseudopus osteoderm from the fissure coded as DE 11.1-3 described along with the Pleistocene herpetofauna by Delfino \& Bailon (2000). The morphology of two of the new anguid osteoderms is perfectly congruent with that from DE 11.1-3 and therefore it seems likely that the Pseudopus did not inhabit the Gargano area during the Pleistocene. This would fit better what is known at the moment about the distribution of Pseudopus: the only Pleistocene 
remains are from localities in northeastern Italy (Delfino, 2002; Delfino et al., 2008). Waiting for further evidences, it is therefore advisable to provisionally remove this taxon from the Pleistocene faunal list of Pirro Nord.

In conclusion, even with the exclusion of Pseudopus, the Pleistocene herpertofaunistic assemblage of the Gargano area is of exceptional relevance. Holman (1998) stated that the Pleistocene European herpetofaunas can be considered rich when they contain 10 species and therefore the Pirro Nord faunistic assemblage, for the taxonomic diversity (at least 18 taxa), good preservation (delicate and tiny structures like anurans'columella auris and carpal elements are preserved), and abundance of fossil remains (tens of thousands), is amongst the most informative of the Mediterranean area.

\section{Acknowledgements}

M. Pavia and G. Pavia (Torino) entrusted us with study of the herpetofaunistic remains of the Torino collection. J.E. González Fernández (Madrid) kindly allowed the extended loan of the Pelobates specimens under his care at MNCN. E. Razzetti (Pavia) and M. Venczel (Oradea) discussed respectively some nomenclatural issues and the validity of various osteological characters. The English summary was translated into German by A. Lutz (Zürich) This paper is framed within a wider project of the University of Florence (coordinator L. Rook) on the evolution of Late Cenozoic vertebrate assemblages. .....

\section{Literature References}

Abbazzi, L., Benvenuti, M., Boschian, G., Dominici, S., Masini, F., Mezzabotta, C., Rook, L., Valleri, G. \& Torre, D. (1996): The Neogene and Pleistocene succession and the mammal 
faunal assemblages of an area between Apricena and Poggio Imperiale (Foggia). - Mem. Boll. Soc. Geol. It., 51: 383-402.

Arzarello, M., Marcolini, F., Pavia, G., Pavia, M., Petronio, C., Petrucci, M., Rook, L. \& Sardella, R. (2006): Evidence of the earliest human occurrence in Europe: the site of Pirro Nord (Southern Italy). - Naturwissenschaften, 94: 107-112.

Bailon, S. (1999): Différenciation ostéologique des anoures (Amphibia, Anura) de France. - In Desse, J. \& Desse-Berset, N. (Eds.): Fiches d'ostéologie animale pour l'Archéologie, Série C: Varia - (Centre de Recherches Archéologiques-CNRS) Valbonne, 38 p.

Bologna, M. \& Mazzotti, S. (2006): Biogeography. In: Sindaco, R., Doria, G., Razzetti, E. \& Bernini, F. (Eds.): Atlas of Italian Amphibians and Reptiles. - (Societas Herpetologica Italica, Edizioni Polistampa) Firenze: 654-677.

De Giuli, C. \& Torre, D. (1984): A microfauna with Allophaiomys pliocaenicus from Gargano (Southern Italy). - Palaeont. It., 73: 116-128.

De Giuli, C., Masini, F. \& Torre, D. (1987): The latest Villafranchian faunas in Italy: the Pirro Nord fauna (Apricena, Gargano). - Palaeont. It., 74: 51-62.

Delfino, M. (1996): Erpetofauna Tardo Villafranchiana di Cava Dell’Erba e Cava Pirro (Foggia, Puglia, Italia). Master thesis, University of Turin, Italy, 194 pp.

-,- (1997): Blanus from the Early Pleistocene of Southern Italy: another small tessera from a big mosaic. In: Böhme, W., Bischoff, W. \& Ziegler, T. (Eds.): Herpetologia Bonnensis. - (SEH) Bonn: 89-97. -,- (2001): Early Pleistocene Lacerta remains from Southern Italy (Apricena, Foggia): is it Lacerta siculimelitensis? In: Viciente, L. \& Crespo, E.G. (Eds.): Mediterranean Basin Lacertid Lizards - A biological approach. - (ICN) Portugal: 21-26.

-,- (2002): Erpetofaune italiane del Neogene e del Quaternario. Ph.D. thesis, University of Modena and Reggio Emilia, 382 p. 
Delfino, M. \& Bailon, S. (2000): Early Pleistocene herpetofauna from Cava Dell’Erba and Cava Pirro (Apulia, Southern Italy). - Herpetol. J., 10: 95-110.

Delfino, M., Bar-Oz, G. \& Weissbrod, L. (2007 a): Recent shrinkage of the range of the eastern spadefoot toad, Pelobates syriacus (Amphibia: Anura): archaeological evidence from the Bronze Age of Israel. - Zool. Midd. East, 40: 45-52.

Delfino, M., Böhme, M. \& Rook, L. (2007 b): First European evidence for transcontinental dispersal of Crocodylus (late Neogene of southern Italy). - Zool. J. Linn. Soc., 149: 293-307.

Delfino, M., Bacciotti, M., Bon, M., Pitruzzella, G., Sala, B. \& Rook, L. (2008): A general overview on the Plio-Quaternary herpetofauna of Veneto. In: Corti, C. (Ed.): Herpetologia Sardiniae. - (Societas Herpetologica Italica / Edizioni Belvedere) Latina: 196-199.

Holman, J.A. (1998): Pleistocene amphibians and reptiles in Britain and Europe. - (New York) Oxford University Press, 254 p.

-,- (2000): Fossil snakes of North America: origin, evolution, distribution, paleoecology. - (Indiana University Press) Bloomington and Indianapolis, 357 p.

Lanza, B., Andreone, F., Bologna, M.A., Corti, C. \& Razzetti, E. (Eds.) (2007). Fauna d’Italia, Vol. XLII, Amphibia. - (Calderini) Bologna, 537 p.

Sanchiz, B. (1998): Salientia. In: Handbuch der Paläoherpetologie. Volume 4. - (Verlag Friedrich Pfeil) München, 275 p.

Sindaco, R., Doria, G., Razzetti, E. \& Bernini, F. (Eds.) (2006): Atlante degli Anfibi e dei Rettili d'Italia / Atlas of Italian Amphibians and Reptiles. - (Societas Herpetologica Italica, Edizioni Polistampa) Firenze, 789 p.

Speybroeck, J. \& Crochet, P.A. (2007): Species list of the European herpetofauna - a tentative update. - Pod@rcis, 8: 8-34.

Stöck, M., Sicilia, A., Belfiore, N.M., Buckley, D., Lo Brutto, S., Lo Valvo, M. \& Arculeo, M. 2008): Post-Messinian evolutionary relationships across the Sicilian channel: mitochondrial 
and nuclear markers link a new green toad from Sicily to African relatives. - BMC Evol. Biol., 8: $56-74$.

Szunyoghy, J. Von (1932): Beiträge zur vergleichenden Formenlehre des Colubridenschädels, nebst einer kraniologischen Synopsis der fossilen Schlangen ungarns mit nomenklatorischen, systematischen und phyletischen Bemerkungen. - Acta Zool., 13: 1-56.

Szyndlar, Z. (1984): Fossil Snakes from Poland. - Acta Zool. Cracov., 28: 1-156.

Vergnaud-Grazzini, C. (1970): Les Amphibiens fossiles du gisement d'Arondelli. - Palaeontol. Ital., 66, 47-65.

Venczel, M. (2000): Quaternary snakes from Bihor (Romania). - (Tării Crişurilor Museum) Oradea, $144 \mathrm{p}$. 


\section{Captions}
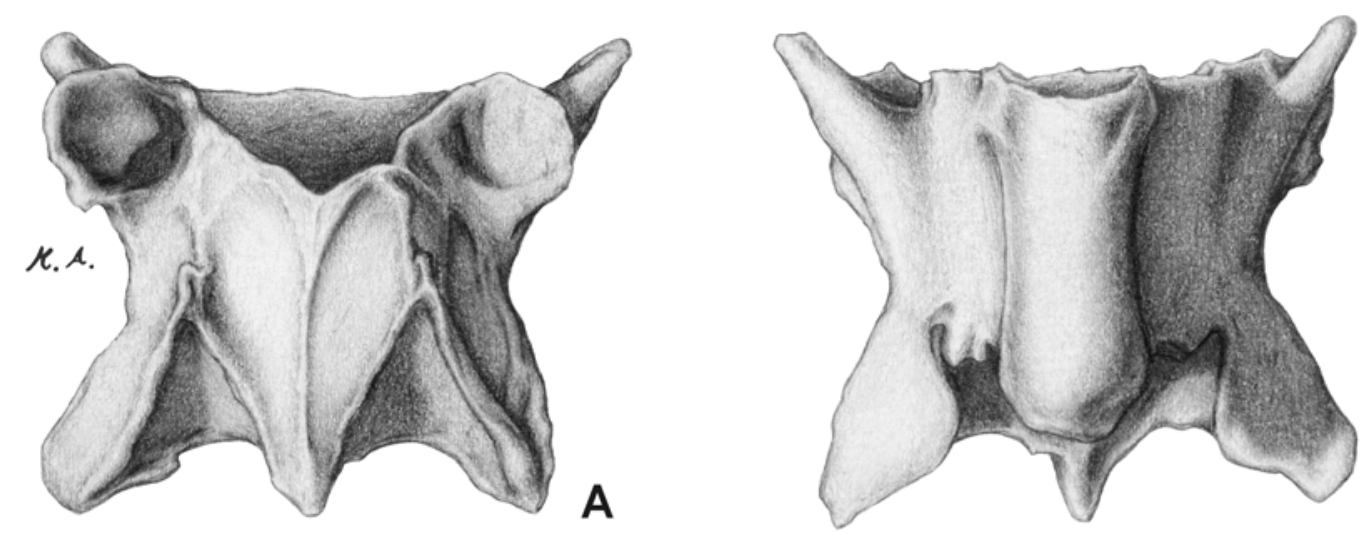

B
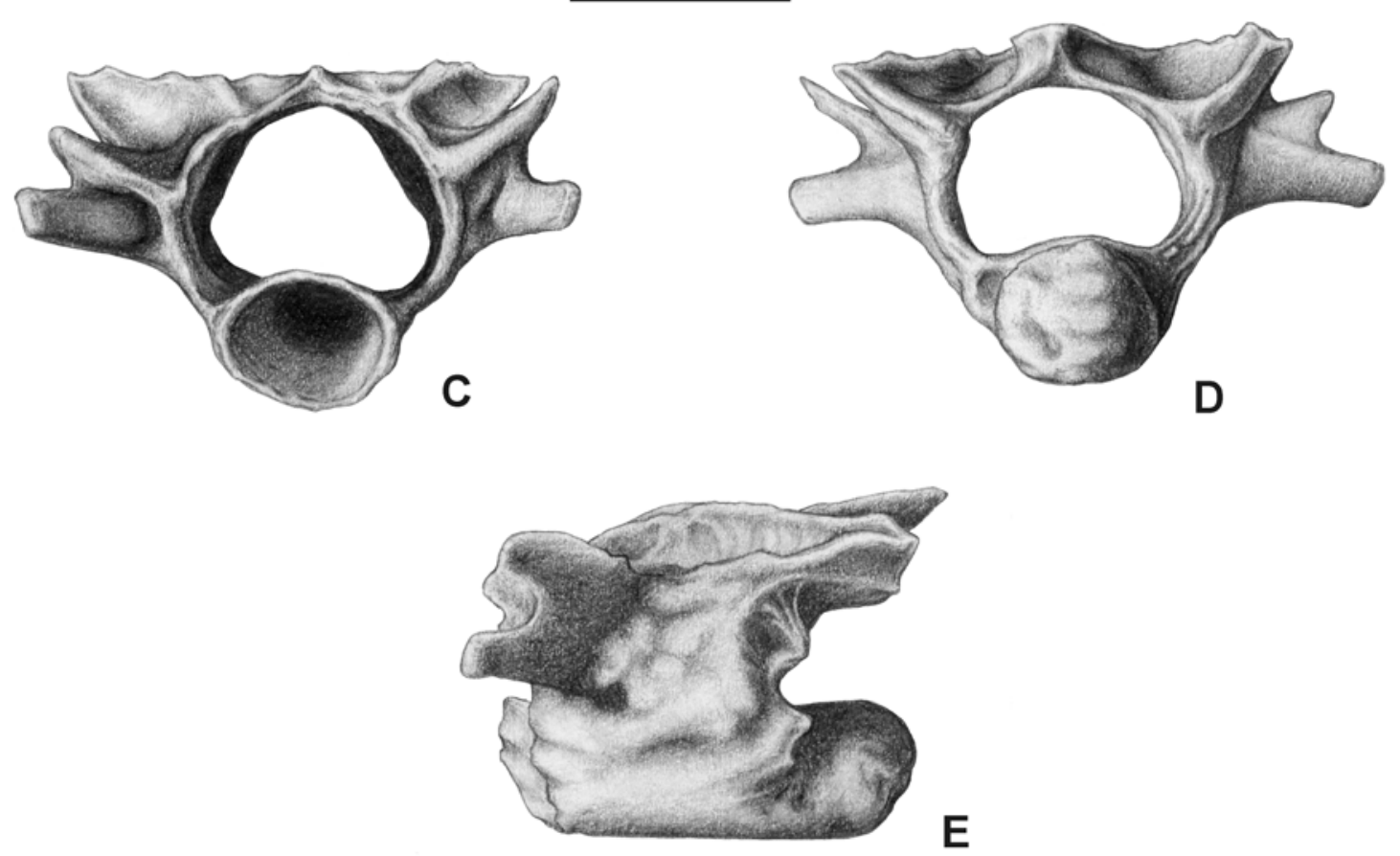

Text-fig. 1. A-E, Pelobates sp., posterior trunk vertebra PU 106783 (PN 21) in dorsal, ventral, anterior, posterior, and left lateral view respectively. Scale bar equals $2 \mathrm{~mm}$. 


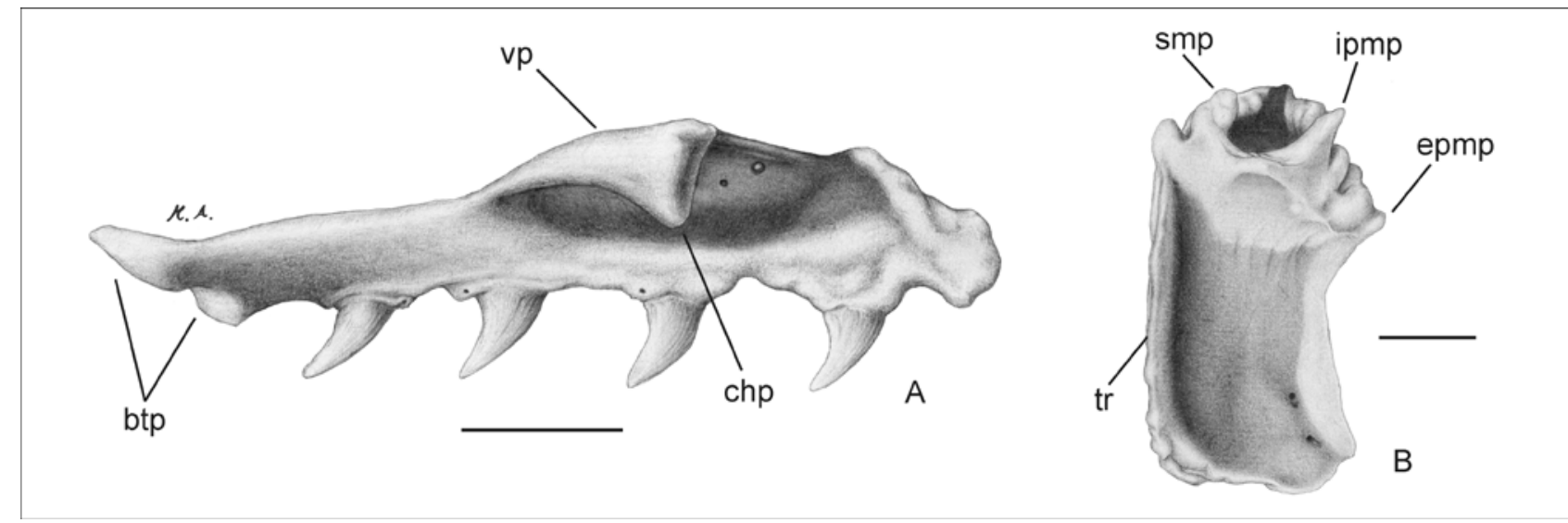

Text-fig. 2. Hierophis viridiflavus. A, left palatine PU 106784 (PN 19) in medial view. B, left frontal 106785 (PN 19) in ventral view. Abbreviations: btp: bifurcated tip for pterygoid; chp: choanal process; epmp: external premaxillary process; ipmp: internal premaxillary process; smp: septomaxillary process; tp: trabecular process; vp: vomerine process. Scale bars equal $2 \mathrm{~mm}$. 


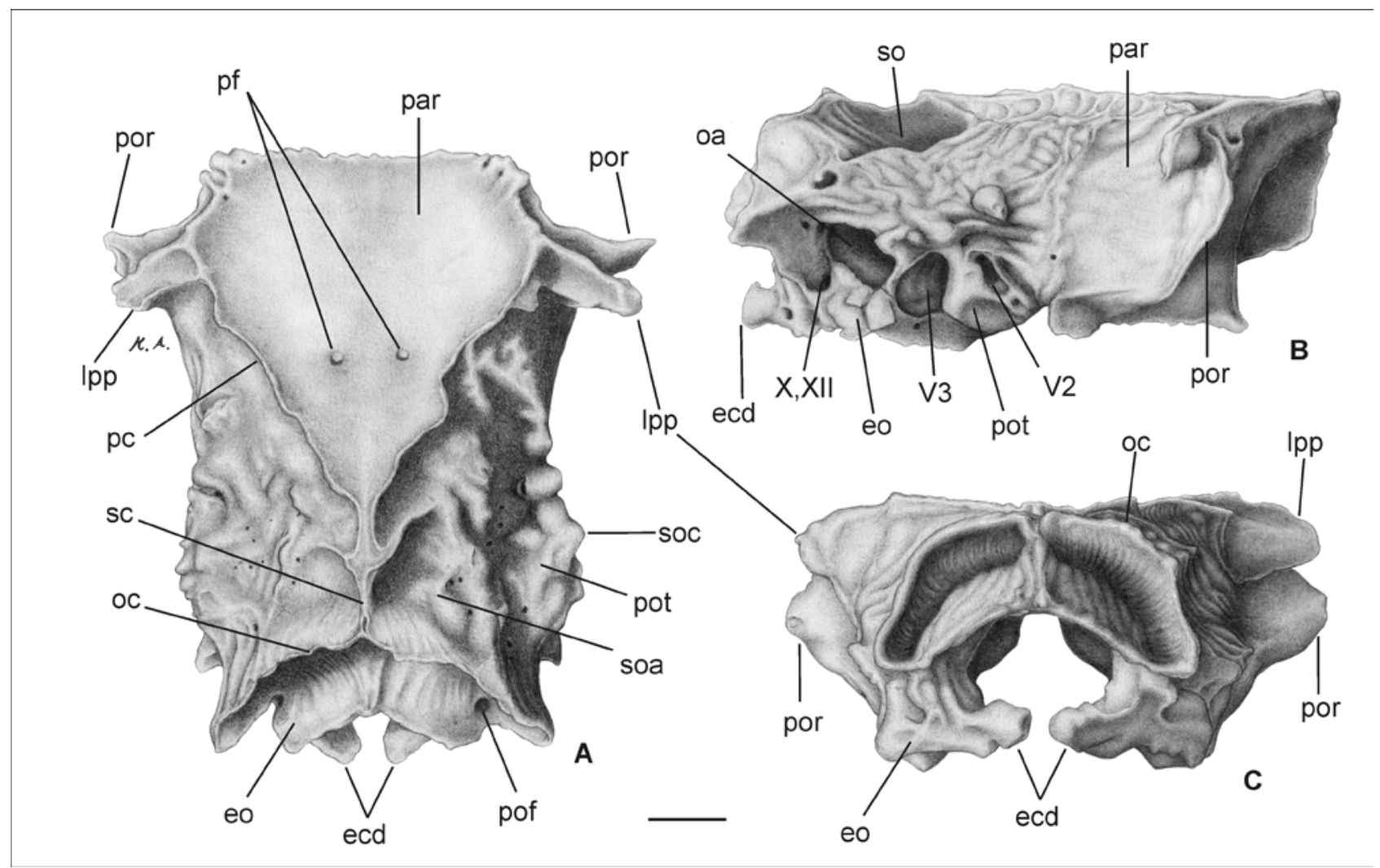

Text-fig. 3. Hierophis viridiflavus. A-C, partially preserved brain case PU 106786 (PN 19) in dorsal, right lateral, and caudal view. Abbreviations: ecd: exoccipital condyle; eo: exoccipital; lpp: lateral process of the parietal; oa: otic aperture (= recessus scalae tympani); oc: occipital crest; par: parietal; pc: parietal crest; pf: parietal foramen; pof: postoccipital foramen; por: postorbital; pot: prootic; sc: sagittal crest; so: supraoccipital; soa: supraoccipial area; soc: supraoccipital crest; V2: foramen for maxillary branch of trigeminal nerve; V3: foramen for mandibular branch of trigeminal nerve; X,XII: vagus-hypoglossal nerve foramen. Scale bar equals $2 \mathrm{~mm}$. 


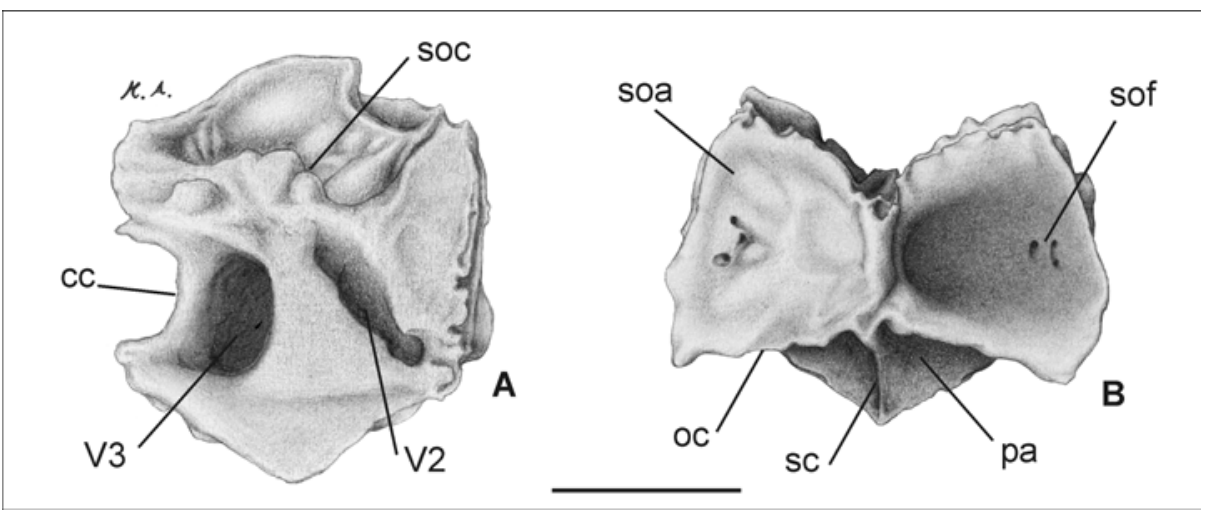

Text-fig. 4. Hierophis viridiflavus. A, right prootic PU 106787 (PN 19) in lateral view. B, supraoccipital PU 106788 (PN 19) in dorsal view. Abbreviations: cc: circumfenestral crest; oc: occipital crest; pa: posterior area; sc: sagittal crest; soa: supraoccipial area; sof: supraoccipital foramen; soc: supraoccipital crest; V2: foramen for maxillary branch of trigeminal nerve; V3: foramen for mandibular branch of trigeminal nerve. Scale bar equals $2 \mathrm{~mm}$.

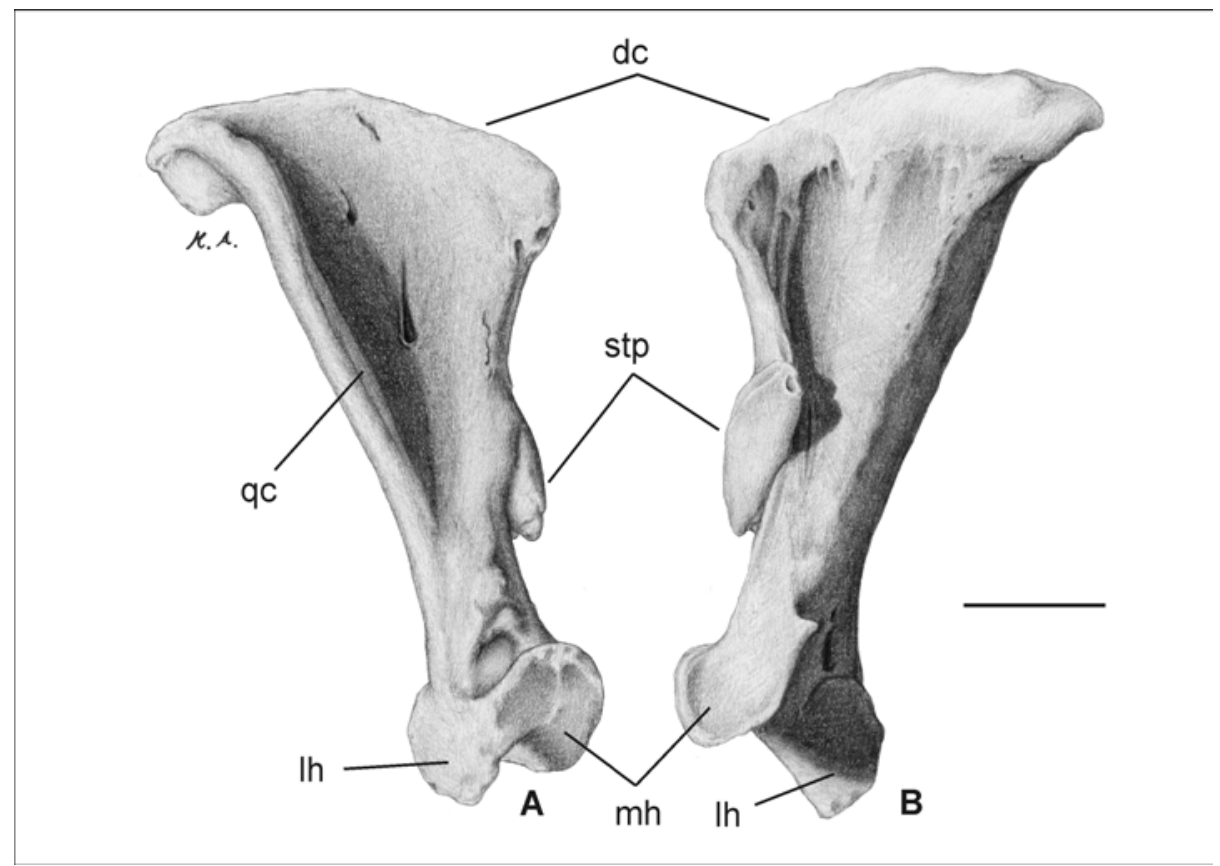

Text-fig. 5. Hierophis viridiflavus. A,B, left quadrate PU 106789 (PN 19) in lateral and medial view. Abbreviations: dc: dorsal crest; lh: lateral hemicondyle; mh: medial hemicondyle; qc: quadrate crest; stp: stapedial process. Scale bar equals $2 \mathrm{~mm}$. 


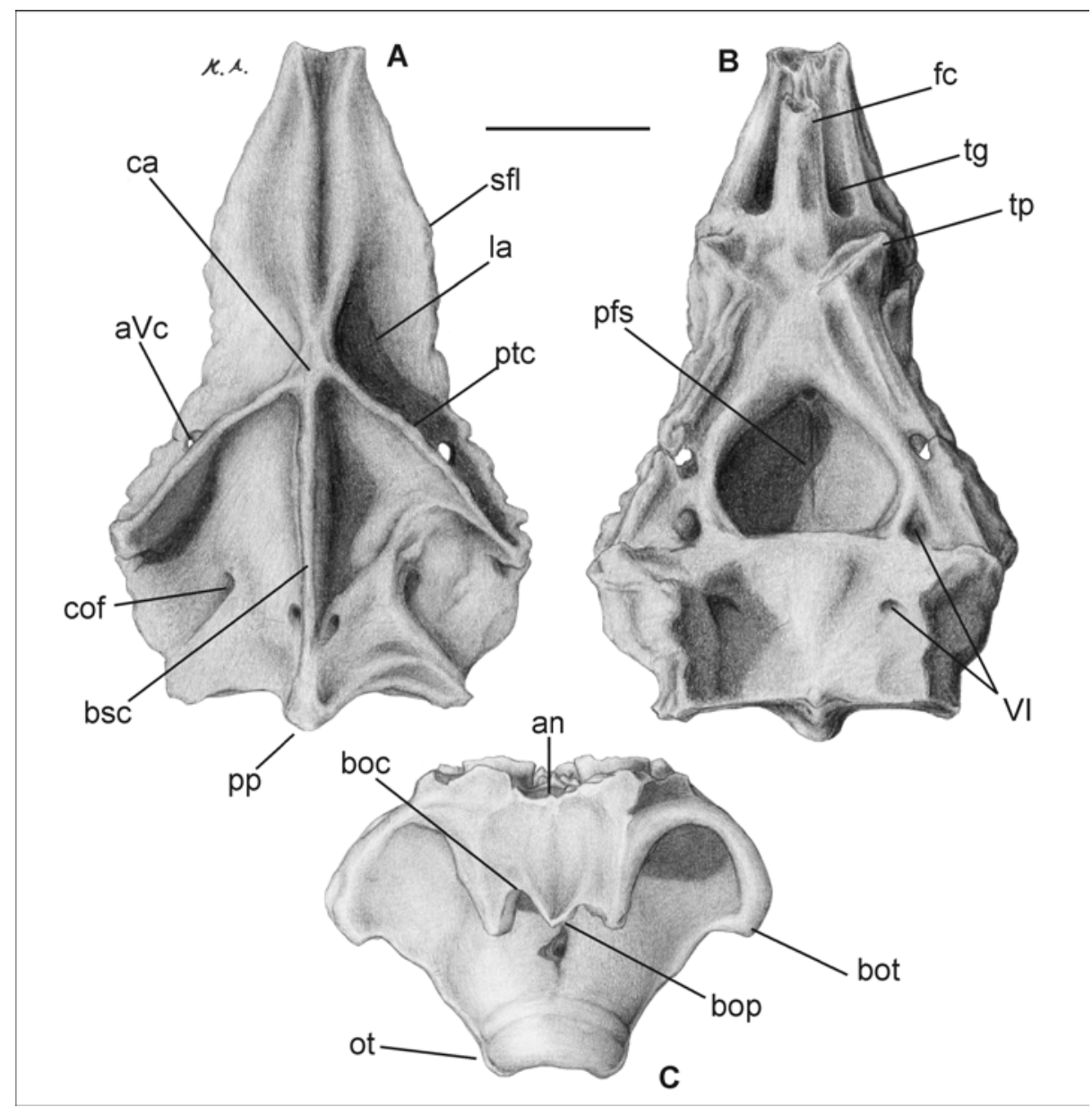

Text-fig. 6. Hierophis viridiflavus. A,B, basiparasphenoid PU 106790 (PN 19) in ventral and dorsal view. C, basioccipital PU 106791 (PN 19) in ventral view. Abbreviations: an: anterior notch; aVc: anterior orifice of Vidian canal; boc: basioccipital crest; bop: basioccipital process; bot: basioccipital tubercle; bsc: basisphenoid crest; ca: central area; cof: common foramen; fc: frontal crest; la: lateral area; ot: occipitocondylar tubercle (= basioccipital condyle); pfs: pituitar fossa; pp: posterior process; ptc: pterygoid crest; sfl: suborbital flange; tg: trabecular groove; tp: trabecular process; VI: abducens nerve foramen. Scale bar equals $2 \mathrm{~mm}$. 


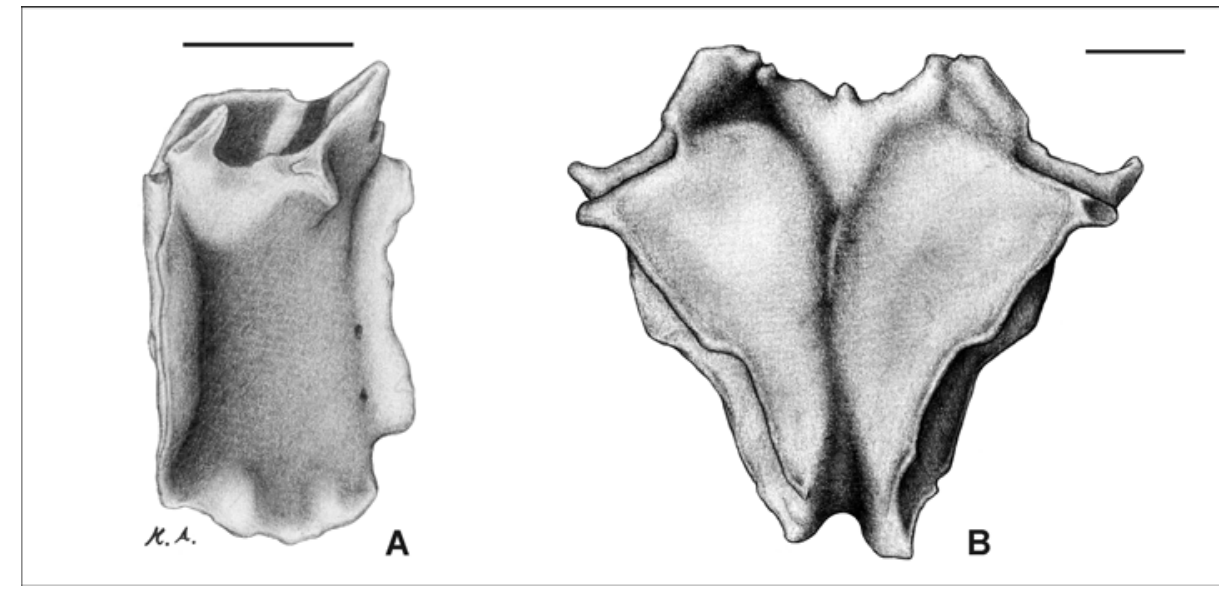

Text-fig. 7. Natrix natrix. A, Left frontal PU 106792 (PN 19), in ventral view. B: parietal PU 106793 (PN 19) in dorsal view. Scale bars equal 2 mm.

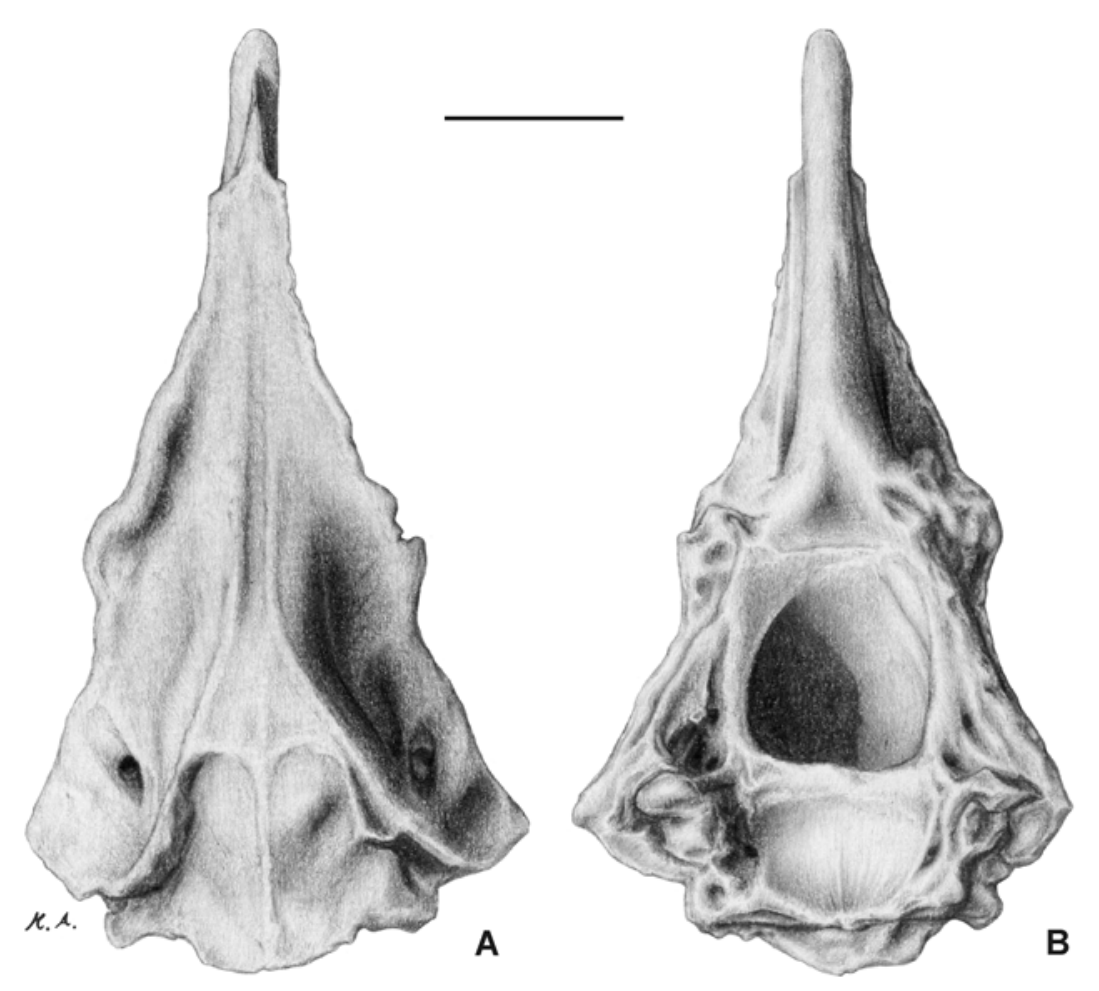

Text-fig. 8. A,B: basiparasphenoid PU 106794 (PN 19) in ventral and dorsal view. Scale bar equals $2 \mathrm{~mm}$. 